\title{
EVALUATION OF CARDIOVASCULAR DRUG POISONINGS REPORTED TO THE DOKUZ EYLUL UNIVERSITY DRUG AND POISON INFORMATION CENTER BETWEEN 2014 AND 2017
}

\author{
Orhan Sahin 1 , Gamze Gokalp ${ }^{2}$, Nil Hocaoglu³ ${ }^{3}$ Engin Yildiztepe $^{4}$, Sule \\ Kalkan ${ }^{3}$ \\ ${ }^{1}$ Dokuz Eylul University, School of Medicine, Department of Medical Pharmacology, Izmir, Turkey \\ 2 Dokuz Eylul University, School of Medicine, Department of Medical Pharmacology, Izmir, Turkey \\ 3 Dokuz Eylul University, School of Medicine, Department of Medical Pharmacology, Division of Clinical Toxicology, \\ Izmir,Turkey \\ ${ }^{4}$ Department of Statistics, Faculty of Arts and Sciences, Dokuz Eylül University, Izmir, Turkey
}

Address for Correspondence Professor of Medical Pharmacology MD Sule Kalkan, E-mail: sule.kalkan@deu.edu.tr
Received: 07.01 .2021 ; Accepted: 03.05.2021; Available Online Date: 27.05 .2021
(C) 0 pyright 2021 by Dokuz Eylül University, Institute of Health Sciences - Available online at https://dergipark.org.tr/en/pub/jbachs

Cite this article as: Sahin O, Gokalp G, Hocaoglu N, Yildiztepe E, Kalkan S. Evaluation of Cardiovascular Drug Poisonings Reported to the Dokuz Eylul University Drug and Poison Information Center Between 2014 and 2017. J Basic Clin Health Sci 2021; 2: 156-161.

\begin{abstract}
Purpose: The purpose of our study is to reveal the demographic features, exposure routes and reasons for exposure, clinical effects and outcomes of cardiovascular drug poisonings reported to the Dokuz Eylul University Drug and Poison Information Center (DEUDPIC) between January 2014 and December 2017. Methods: This retrospective, descriptive, and cross-sectional study was approved by the Noninvasive Research Ethics Committee of Dokuz Eylül University School of Medicine. All data were recorded on standard data forms and then transferred to a software (Ruber, written by Engin Yildiztepe, 2007) for data analysis.

Results: There were 43 poisonings cases were reported with cardiovascular drugs. Female cases were common $(60.47 \%)$. Half of the poisoning cases were toxic $(51.16 \%)$. The most common reason of poisonings was intentional $(81.40 \%)$. All of cases between 13-49 age group were intentional exposures. Only single substance intakes were responsible for the most of the drug exposures $(62.79 \%)$. The most common agents were beta-blockers $(29.85 \%)$, medicines that affect the renin-angiotensin system $(23.88$ $\%)$, calcium channel blockers $(11.94 \%)$ and cardiac therapy drugs such as digoxin (11.94\%). Clinical signs and symptoms were classified as asymptomatic (37.21\%), mild $(23.26 \%)$, moderate $(23.26 \%)$, and severe $(4.65 \%)$. Recommended treatments were observation and supportive care $(46.67 \%)$, decontamination methods $(44.00 \%)$ and antidote therapy $(2.67 \%)$. One fatality was reported.

Conclusions: We suggest that determination of the epidemiological characteristics of cardiovascular drug exposures in our country through prospectively multi-centered studies may provide significant contributions to prevent poisonings and decrease the mortality and morbidity of the cases.
\end{abstract}

Keywords: Cardiovascular drugs, Drug and Poison Information Center, Poisoning and Toxicity. 


\section{INTRODUCTION}

Cardiovascular drugs (CVDs) are widely used to treat various cardiovascular diseases such as hypertension, arrhythmia, angina, heart failure, hyperlipidemia, and others (1). Among the most commonly used drug groups in cardiovascular disease management are calcium channel blockers, beta-blockers, ACE inhibitors, diuretics, and lipid-lowering drugs (1-3). Turkey Health Statistics 2016 has reported that the digestive system and metabolism drugs are the first drugs in pharmaceutical consumption per 1.000 population by years. The second one is the cardiovascular system drugs (4). The widespread use and prescription of these drugs may lead to drugrelated problems such as drug interaction, adverse reactions, and acute or chronic poisonings. The various clinical effects seen in overdose with these drugs are cardiac (hypotension, bradycardia, AV block, fatal dysrhythmias, cardiogenic shock) and noncardiac (syncope, lethargy, metabolic acidosis, seizures, coma) manifestations and death (5).

The American Association of Poison Control Centers (AAPCC) reports that cardiovascular drug poisonings were involved seventh with $4.14 \%$ among human exposures. It was also reported that cardiovascular poisonings were placed fourth among the most significant rate of exposure increase. Of the 1196 pharmaceutical poisonings that resulted in death, 216 $(17.9 \%)$ were reported to be related to cardiovascular drugs (6). In Turkey, according to Dokuz Eylul University Drug and Poison Information Center
(DEUDPIC), CVD related poisonings accounted for $4.4 \%$ of consulted patients between 1993 to 2006 (7). Between 2009 and 2014, in a study evaluating suicidal intoxications with cardiovascular drugs at the emergency department of two state hospitals in Turkey, cardiovascular drugs were reported to be responsible for $81(5.9 \%)$ out of a total of 1399 suicide attempts (8). Beta-blockers and calcium channel blockers (CCBs) are responsible for acute and fatal cardiovascular drug poisonings in many countries (6-9). There is no recent epidemiological study on cardiovascular drug poisonings in Turkey.

The purpose of our study is to reveal the demographic features, exposure routes and reason for exposure, clinical effects, and outcomes of cardiovascular drug poisonings reported to Dokuz Eylul University Drug and Poison Information Center (DEUDPIC) between January 2014 and December 2017. We believe that the determination of the epidemiological characteristics of CVD exposures in our country through prospectively multi-centered studies may provide significant contributions to prevent poisonings and decrease the mortality and morbidity of the cases.

\section{METHODS}

This study started upon the Dokuz Eylul University's approval, School of Medicine Noninvasive Ethics Committee (protocol number: 3632-GOA). A crosssectional, retrospective, and descriptive review of all cases exposed to cardiovascular drugs (CVDs)

Table 1. The distribution of cases by the cause of exposure and age

\begin{tabular}{|l|l|l|l|l|l|l|l|l|l|}
\hline & \multicolumn{2}{l|l}{ Intentional } & \multicolumn{2}{l|}{ Unintentional } & \multicolumn{2}{l|}{ Unknown } & \multicolumn{2}{l|}{ Total } \\
\hline Age groups,year & $\mathrm{n}$ & $\%$ & $\mathrm{n}$ & $\%$ & $\mathrm{n}$ & $\%$ & $\mathrm{n}$ & $\%$ \\
\hline $0-5$ & 0 & 0.00 & 1 & 100.00 & 0 & 0.00 & 1 & 100.00 \\
\hline $6-12$ & 0 & 0.00 & 0 & 0.00 & 0 & 0.00 & 0 & 100.00 \\
\hline $13-18$ & 4 & 100.00 & 0 & 0.00 & 0 & 0.00 & 4 & 100.00 \\
\hline $19-29$ & 12 & 100.00 & 0 & 0.00 & 0 & 0.00 & 12 & 100.00 \\
\hline $30-39$ & 2 & 100.00 & 0 & 0.00 & 0 & 0.00 & 2 & 100.00 \\
\hline $40-49$ & 11 & 100.00 & 0 & 0.00 & 0 & 0.00 & 11 & 100.00 \\
\hline $50-59$ & 1 & 50.00 & 1 & 50.00 & 0 & 0.00 & 2 & 100.00 \\
\hline $60-69$ & 4 & 57.14 & 2 & 28.57 & 1 & 14.29 & 7 & 100.00 \\
\hline $70-$ & 1 & 25.00 & 3 & 75.00 & 0 & 0.00 & 4 & 100.00 \\
\hline Total & 35 & 81.40 & 7 & 16.28 & 1 & 2.32 & 43 & 100.00 \\
\hline
\end{tabular}


reported to the DEUDPIC in Izmir from January 2014 and December 2017 was evaluated.

In our study, we considered all cases of' exposure, whether accidentally or intentionally. The data collected from the standard data forms via phone interviews and then entered into a software (Ruber, written by Engin Yildiztepe, 2007) were as follows: demographic data, CVDs type, exposure routes and reason for the exposure, time, clinical effects, treatment methods, length of hospital stay and outcomes (complete recovery or death). Cases age was classified as 0 to 18 for children, 19 and more for adults. The CVDs are classified into eight groups: Beta blocking agents, medicines that affect the reninangiotensin system, calcium channel blockers, diuretics, lipid-modifying agents, vasoprotectives, antihypertensives, and cardiac therapy (such as digoxin).

The clinical signs and symptoms were categorized as asymptomatic, mild, moderate, or severe using the International Programme on Chemical Safety, the European Union Commission, and the European Association of Poison Centres and Clinical Toxicologists (IPCS/EC/EAPCCT).

\section{Statistical Analyses}

The data were recorded in the "Statistical Package for Social Sciences for Windows 22.0" program (IBM SPSS; Armonk, NY, USA). The Pearson Chi-Square test was used for data analysis. Data were presented as mean \pm standard error and percentage (\%). P $<0.05$ values were considered as significant.

\section{RESULTS}

Between 2014 and 2017, 448 poisonings were reported to the DEUDPIC, and $43(9.60 \%)$ of them were CVDs exposures. Most of the cases were adult. The adults' percentage was $88.37 \%$ (38 cases), and children were $11.63 \%$ ( 5 cases). The female-to-male ratio was $1.53 / 1(60.47 \%, 26$ females, and $39.53 \%$,
17 males). The mean age was $41.44 \pm 3.17$ years (14.60 \pm 3.16 and $44.97 \pm 3.14$ years for children and adults, respectively).

Most of the cases were reported in summer and autumn $(60.46 \%, 26)$. The average passing time until the consulting to (DEUDPIC) by telephone after exposure to CVDs was $10.12 \pm 3.54$ hours (3.5 \pm 1.82 and $11.12 \pm$ 4.05 hours for children and adults, respectively). Most of the calls were detected within the first 4 hours $(48.84 \%)$. The primary type of CVDs exposure was acute $(69.77 \%$ of the cases). Chronic exposures were $9.30 \%$ of all cases, and acute exposures depend on chronic exposures were $18.60 \%$. The type of CVDs exposure in $2.33 \%$ of the cases was unknown.

In all cases, the route of the exposure was ingestion. Intentional exposure was the most common reason for poisonings $(81.40 \%, 35)$. Compared to poisonings in adults and children, intentional exposures were more common in adults $(88.57 \%, 31$ and $11.43 \%, 4$, respectively). Accidental exposures were $16.28 \%$, and unknown reasons were $2.32 \%$ of all cases.

Accidental poisonings occurred mainly in the $0-6$ age group $(100.0 \%, 1)$ and over 69 ages $(75.0 \%, 3)$. Suicidal attempts were predominant in the 13-49 age group $(82.86 \%, 29)$. In all intentional exposures, females were predominant $(65.71 \%, 23)$. When we compared the causes of poisoning and age groups, there was no significant difference between children and adults $(p=1.000, x 2=0,045$, Table 1$)$. When we compared the causes of poisoning and sex differences, there was no significant difference between females and males $(p=0.477, x 2=1,292$, Table 2).

Only single substance ingestions were responsible for most of the drug exposures $(62.79 \%)$. Multiple substance intakes were $37.21 \%$ of all cases. The most common drugs were beta-blockers $(29.85 \%)$, agents acting on the renin-angiotensin system $(23.88 \%)$ and calcium channel blockers (11.94\%), and cardiac therapy drugs such as digoxin $(11.94 \%$

Table 2. Distribution of cause exposure by sex

\begin{tabular}{|l|l|l|l|l|l|l|}
\hline & \multicolumn{2}{l|}{ Female } & \multicolumn{2}{l|}{ Male } & \multicolumn{2}{l|}{ Total } \\
\hline Cause & $\mathrm{n}$ & $\%$ & $\mathrm{n}$ & $\%$ & $\mathrm{n}$ & $\%$ \\
\hline Intentional & 23 & 65.71 & 12 & 34.29 & 35 & 100.00 \\
\hline Unintentional & 3 & 42.86 & 4 & 57.14 & 7 & 100.00 \\
\hline Unknown & 0 & 0.00 & 1 & 100.00 & 1 & 100.00 \\
\hline Total & 26 & 60.47 & 17 & 39.53 & 43 & 100.00 \\
\hline
\end{tabular}


(Table 3). The three most common agents are metoprolol with 9 cases, propranolol with 5 cases, and ramipril with 5 cases.

When categorized according to the amounts of substances, toxic, non-toxic, and unknown were accounted for $51.16 \%$ (34.88\% female and $16.28 \%$ male), $13.95 \%$ (9.30\% female and $4.65 \%$ male), and $34.88 \% \quad(16.28 \%$ female and $18.60 \%$ male), respectively. When we compared to amounts of substances and sex differences, there was no significant difference between females and males $(p=0.399, x 2=1.839$, Table 4).

The clinical signs were graded as asymptomatic (37.21\%), mild (23.26\%), moderate $(23.26 \%)$, and severe (4.65\%). In an asymptomatic group, $32.56 \%$ were intentional intakes, and $4.65 \%$ were unintentional intakes. These rates were $20.93 \%$ and $2.33 \%$ in the mild symptomatic group, $13.95 \%$ and $9.30 \%$ in the moderate symptomatic group, and $2.33 \%$ and $0.00 \%$ in the severe symptomatic group. Cardiovascular system manifestations $(39.47 \%, 15)$ were predominant, followed by the central nervous system $(36.84 \%, 14)$ and gastrointestinal manifestations $(7.89 \%, 3)$. Hypotension was the most common cardiovascular sign $(40.0 \%, 6)$. There was no significant difference between clinical signs and the causes of poisoning $(p=0.655, \times 2=0.757)$.

Observation and supportive care procedures were recommended in $46.67 \%$ of cases by DEUDPIC. The rate of recommended decontamination methods was $44.00 \%$. Specific antidote treatment was recommended in two cases exposed to propranolol and amlodipine (2.67\%). One fatality was reported with digoxin exposure.

\section{DISCUSSION}

In this study, we analyzed cardiovascular drugs (CVDs) exposures reported to the DEUDPIC in Izmir. During four years, 448 poisonings were consulted, and $43(9.60 \%)$ were CVDs exposures. According to the American Association of

Table 3. Cardiovascular drugs responsible for poisoning exposures

\begin{tabular}{|c|c|c|c|}
\hline Cardiovascular drugs types & Cardiovascular drugs subgrups & $\mathrm{n}$ & $\%^{*}$ \\
\hline Beta blocking agents & $\begin{array}{l}\text { Metoprolol (9) } \\
\text { Propranolol (5) } \\
\text { Nebivolol (3) } \\
\text { Carvedilol (2) } \\
\text { Bisoprolol (1) } \\
\end{array}$ & 20 & 29.85 \\
\hline Agents acting on the renin-angiotensin system & $\begin{array}{l}\text { Ramipril (5) } \\
\text { Valsartan (4) } \\
\text { Captopril (2) } \\
\text { Perindopril (2) } \\
\text { Telmisartan (2) } \\
\text { Irbesartan (1) }\end{array}$ & 16 & 23.88 \\
\hline Cardiac therapy & $\begin{array}{l}\text { Digoxine (3) } \\
\text { Trimetazidine cyclandelate (3) } \\
\text { Amiodarone (1) } \\
\text { Metoxamine (1) }\end{array}$ & 8 & 11.94 \\
\hline Calcium channel blockers & $\begin{array}{l}\text { Amlodipine (4) } \\
\text { Nifedipine (2) } \\
\text { Verapamil (1) } \\
\text { Diltiazem (1) }\end{array}$ & 8 & 11.94 \\
\hline Diuretics & $\begin{array}{l}\text { Hydrochlorothiazide (3) } \\
\text { Furosemide (3) } \\
\text { Indapamide (1) }\end{array}$ & 7 & 10.45 \\
\hline Lipid modifying agents & $\begin{array}{l}\text { Atorvastatin (3) } \\
\text { Rosuvastatin (1) }\end{array}$ & 4 & 5.97 \\
\hline Vasoprotectives & Diosmin (3) & 3 & 4.48 \\
\hline Antihypertensives & Metildopa (1) & 1 & 1.49 \\
\hline Total & & 67 & 100.00 \\
\hline
\end{tabular}

*Percentages are based on the total number (67) of medications. 
Table 4. Distribution of the amount of CVDs exposures by sex

\begin{tabular}{|l|l|l|l|l|l|l|}
\hline & \multicolumn{2}{l|}{ Female } & \multicolumn{2}{l|}{ Male } & \multicolumn{2}{l|}{ Total } \\
\hline Amount & $\mathrm{n}$ & $\%$ & $\mathrm{n}$ & $\%$ & $\mathrm{n}$ & $\%$ \\
\hline & & & & & & \\
\hline Toxic & 15 & 34.88 & 7 & 16.28 & 22 & 51.16 \\
\hline Unknown & 7 & 16.28 & 8 & 18.60 & 15 & 34.88 \\
\hline Non-toxic & 4 & 9.30 & 2 & 4.65 & 6 & 13.95 \\
\hline
\end{tabular}

* Percentages are based on the total number (43) of poisoning cases

Poison Control Centers (AAPCC), CVDs were the cause of $4.14 \%$ of the drug poisonings and $8.6 \%$ in a study from Yekaterinburg, Russia $(6,10)$. In a study from Turkey between 1993-2006, Kalkan et al. reported that this ratio was $4.4 \%$. The other study evaluated suicidal intoxications with cardiovascular drugs at the emergency department from Turkey between 2009-2014; this ratio was $5.9 \%(7,8)$. Compared to these rates, our percentage $(9.60 \%)$ was similar to a study from Yekaterinburg, Russia but was lower than from the 2016 Annual Report of AAPCC $(6,10)$. Compared to the data from previous years, we found an increased rate of exposure to CVDs in Turkey.

In our study, only single substance ingestions were responsible for most drug exposures (62.79\%). Differently, in a study by Ayhan et al., they found that most of the patients $(71.6 \%)$ was multidrug ingestions (8). The most common cardiovascular drugs were beta-blockers $(29.85 \%)$, agents acting on the reninangiotensin system $(23.88 \%)$, and calcium channel blockers (CCBs) (11.94\%), and cardiac therapy drugs (digoxin, etc.) in our study. Similarly, in another study conducted by AAPCC, the most frequently exposed CVDs (106.572 cases) were beta-blocker agents (26.267 cases), agents acting on the renin-angiotensin system (25.186 cases), and CCBs (13.350 cases) (6). In a previous study by Kalkan et al., during 14 years, CCBs and beta-blockers were the most common CVDs in poisonings $(19.7 \%$ and $17.3 \%$, respectively) (7). In another study from Turkey, the most common cardiovascular drugs were angiotensin-converting enzyme inhibitors (39.5\%) and beta-blockers $(37.0 \%)$ (8). In many countries, CCBs and beta-blockers are the most responsible for cardiovascular drug poisonings $(9,10)$. In this respect, beta-blockers were still one of the most common reasons for poisoning by CVDs. In this study, compared to data from our previous study (3.9\%), it is seen that there has been an increase in the number of agents acting on the renin-angiotensin system exposures (23.88\%) (7). A study from Bangladesh investigated cardiovascular disease prevalence and prescription patterns at a tertiary level hospital. One of the most frequently used antihypertensive drug classes was agents acting on the renin-angiotensin system (ACE inhibitors:30.13\% and angiotensin receptor blockers:13.95\%) (2). Turkey's study reported that angiotensin-converting enzyme (ACE) inhibitors were the fifth most preferred antihypertensive drug class. Renin-angiotensin system blockers have been reported as the most preferred antihypertensive drugs in patients with diabetic and chronic renal diseases. Also, they reported that the most common dual therapy was an ARB and a diuretic, followed by an ACE inhibitor and a diuretic (11). In our study, an increase in the number of agents acting on the renin-angiotensin system exposures can be explained by the information that these drugs were the most common in dual therapy and patients with comorbidities.

In our study, females were predominant, and our reports confirm the previous studies (7-9). Also, we found that the most common CVDs exposures were intentional. We observed that suicidal attempts were predominant in adolescents and young adults. Mostly, between 15 and 49 ages were the most vulnerable. In the previous studies from our country, similar findings were reported $(7,8)$.

In this study, most of the poisoning cases $(51.16 \%)$ were graded as toxic. This ratio is similar to our previous results $(54.3 \%)(7)$. Although half of all exposures were toxic, most cases were asymptomatic (37.21\%) or had mild symptoms $(23.26 \%)$. In this study, supportive care and decontamination methods were recommended in most cases $(46.67 \%$ and 
prescription patterns at a tertiary level hospital in Bangladesh. J Appl Pharm Sci 2012; 2: 80-84

Sahin O et al Evaluation of Cardiovascular Drug Poisonings
$44.00 \%$, respectively). We only reported death in one case due to digoxin exposure. In a study by Ayhan et al., one death was reported due to beta-blocker (8). According to the AAPCC, 215 fatalities were reported due to CVDs (56 amlodipine, 26 diltiazem, 20 metoprolol, 17 verapamil, 14 digoxin, 14 propranolol, 10 carvedilol, 9 diltiazem [extended release], 8 betablocker) (6). Our mortality rate was lower than the AAPCC because of our service as a local poison counseling center.

\section{Limitations}

Because of retrospective data, we could not reach some data. All information on the substance taken was self-reported. There may be a lack of some information.

\section{CONCLUSION}

Our study shows an increase in exposures with CVDs in Turkey. On the other hand, there is a significant increase in the number of agents acting on the reninangiotensin system exposures. At the same time, betablockers are still the most common reason for poisoning by CVDs. Turkey Health Statistics reported that the second commonly consumed drugs are cardiovascular drugs in our country. We have known that most patients with suicidal attempts tend to commit suicide with their drugs. The widespread use of these drugs can explain the increase in the frequency of poisoning with cardiovascular drugs. Therefore, rational cardiovascular drug therapy is important for reducing exposure to cardiovascular drugs. We believe that the determination of the epidemiological characteristics of CVDs exposures in our country through prospectively multi-centered studies may provide significant contributions to prevent poisonings and decrease the mortality and morbidity of the cases.

Acknowledgments: This study was presented as an oral presentation at the 3rd Regional TIAFT Meeting in Turkey, The International Association of Forensic Toxicologists, in Nevsehir, Turkey, 2018.

Conflicts of Interest: All of the authors declare that there are no conflicts of interest in connection with this paper.

Funding: There is no funding

\section{REFERENCES}

1. Rang HP, Ritter JM, Flower RJ, Henderson G. The hearts. In: Rang HP, Ritter JM, Flower RJ, Henderson G, editors. Rang\&Dale's Pharmacology. 8th ed. China:Elsevier; 2016.p. 247-260.

2. Muhit A, Rahman $\mathrm{O}$, Raihan $\mathrm{SZ}$, et al. Cardiovascular disease prevalence and
3. Rahman A, Raka SC, Ahmed SM. Prevalence of cardiovascular diseases and prescription patterns in a randomly selected population in Bangladesh. Biomed Pharmacol J 2017; 10: 607-613.

4. Kose MR, Başara BB, Çağlar SI, et al. General directorate of health research, Republic of Turkey Ministry of Health, Health Statistic Year Book 2016: 2017. Ministry of Health Publication No: 1084.

5. Meenakshisundaram R, Cannie DE, Shankar PR, Zadeh HZ, Bajrachary $O$, Thirumalaikolundusubramania $P$. Cardiovascular Toxicity of Cardiovascular Drugs. In: Meenakshisundaram R, Thirumalaikolundusubramania $\mathrm{P}$, editors. Heart and Toxins. New York: Elsevier; 2015.p.225-274.

6. Gummin DD, Mowry JB, Spyker AD, Brooks DE, Fraser MO, Banner W. 2016 Annual report of the American Association of Poison Control Centers' National Poison Data System (NPDS): 34th Annual Report, Clin Tox (Phila) 2017; 55: 1072-1252.

7. Kalkan S, Hocaoglu N, Oransay K, Unverir $P$, Tuncok Y. Cardiovascular medication exposures reported to Drug and Poison Information Center (DPIC) in Izmir, Turkey: A 14-year experience. Hum Exp Toxicol 2011; 34: 53-60.

8. Ayhan H, Ozucelik DN, Dogan H, Erdogan MO, Yigit $Y$. Suicidal cardiovascular drug intoxication in emergency department. HSP 2015; 2: 329-333.

9. Zeinvand M, Hoseini T, Rahmani A. A Clinicoepidemiological study on poisonings due to cardiovascular drugs in Ahvaz, Iran. Asia Pac J Med Toxicol 2017; 6: 25-28.

10. Brusin KM, Sentsov VG, Krayeva YV, Kondrashov DL, Lund C, Hovda KE. Poisonings by cardiovascular drugs in Yekaterinburg, Russia. Asia Pac J Med Toxicol 2016; 5: 3-10.

11. Yuruyen G, Toprak ID, Toprak Z, et al. Choice of treatment based on Turkish hypertension consensus report: Do we follow the recommendations? Turk Kardiyol Dern Ars 2018; 46: 25-31. 